workers as a personal, enjoyable and stimulating survey of the study of enzyme mechanisms, which demands little prior knowledge of the subject and is reasonable in price.

K. Dalziel

\section{INTRACELLULAR MEMBRANES}

\section{Intracellular Membraneous Structure}

(Proceedings of the lst International Symposium for Cellular Chemistry.) Edited by S. Seno and E. V. Cowdry. Pp. xix +588. (Okayama, Japan: Japan Society for Cell Biology, 1965.) 14 dollars.

CCIENTIFIC conferences and symposia are nowadays $\$$ frequently followed by publication of an edited version of the proceedings in elaborate book-form. The question arises whether these volumes are a worth-while investment bearing in mind the cost, inevitable time lag in publication, and the probability that the contributors will in any case report their observations elsewhere. In spite of these material drawbacks, the bound volume can certainly, sometimes, be justified, either through well-judged timing of the symposium or perhaps the authoritative nature of particular contributions. On both of these counts there is much to recommend the special Katsunuma Memorial issue from the Japan Society for Cell Biology, entitled Intracellular Membraneous Structure.

The meeting was held at Ohtsu, during March 1963, and it is clear that from a technical point of view much of the work presented reached a very high standard. The invited speakers were concerned primarily with ultrastructural aspects of cell physiology and pathology; and the papers are divided into six sections covering various categories of cell membranes. Original references, and a transcript of the discussion that followed the verbal presentations, are included. Altogether there are 43 papers (all in English) mostly emanating from laboratories in Japan and the United States. Numerous first-rate and wellreproduced electron micrographs are included as illustrations.

In the opening section, "Endoplasmic Reticulum", D. W. Fawcett describes the varying patterns of granular and agranular reticulum in cells of the mammalian pancreas, liver and testis, in different functional states. There is discussion of the possible role of the endoplasmic reticulum and the Golgi apparatus in the formation of secretory products. Several later papers touch on this question, and serve to illustrate clearly one of the difficulties most commonly met with in biological electron microscopy; namely, the interpretation of profiles that seem to suggest a dynamic inter-relation of cell components. Interesting papers by E. Yamada on membranelimited elements in retinal cells of the cat, and by $\mathrm{Y}$. Miura and $\mathrm{H}$. Itoh on fibroin-synthesizing vesicles in silk-glands, are included in this section. Next, under "Mitochondria and Related Structure", two papers from D. E. Green and associates and another from F. S. Sjöstrand give an instructive view of present-day thought (much of it rather speculative) on ultrastructure, chemistry and function in mitochondrial membranes. Papers on the morphology of chloroplasts also appear in this chaptor.

All microscopists who have ever been fascinated and perplexed by the Golgi controversy, dating from 1898 when Dr. Golgi reported the "apparato reticulare interno" in certain neurones, will acknowledge gratefully the contribution of electron microseopy towards recent clarification of this problem. Out of nine papers on the subject in this symposium two of special interest are by G. C. Hirseh, who strives convincingly to correlate the earlier images, based on methods of light microscopy, with the complex patterns of membranous lamellae and vesicles now familiar to electron microscopists. Further consideration of the role of the Golgi apparatus in secretory cells is presented by $\mathrm{L}$. Herman and associates in a technically most impressive contribution, and the recent extension of cytochemical methods to the ultrastructural level is elegantly demonstrated by A. B. Novikoff in a comprehensive account of enzymatic activities and possible functional inter-relation of the various intracellular membrane systems. Notable in later sections of the book are an assessment by C. A. Baud of possible morphological pathways for nucleo-cytoplasmic exchange of materials; and reviews by J. D. Robertson on the present status of the unit membrane concept, and by $\mathrm{E}$. V. Cowdry on the intracellular distribution of water. Finally, there are papers on the outer cell membrane itself, and mechanisms of transportation across it; these include reports on synaptic morphology, on the absorption of fat by cells of the intestinal epithelium, and on various examples of endocytotic activity.

In spite of its rather high price, this book can be recommended as a well-produced, up-to-date and potentially useful acquisition for the bookshelves of cell biologists.

J. A. Armstrong

\section{A LAYMAN'S LOOK AT BACTERIA}

\section{Focus on Bacteria}

By Emmy Klieneberger-Nobel. With a chapter on the Mycoplasmataceae by Ruth M. Lemcke. Pp. vii +145. (London: Academic Press, Inc. (London), Ltd.; New York: Academic Press, Inc., 1965.) 32s. $6 d$.

TN several ways, Focus on Bacteria is an odd little book. The jacket flap says it "is not intended for the specialist but for the lay person with keen scientific interest". The author's foreword states: "The purpose of this book is first and foremost to show that nature has a quality of beauty even in her smallest manifestations".

The first chapter is a brief historical sketch of the development of bacteriology as a science, covering the fundamental discoveries of the father of microbiology, Antony van Leeuwenhoek, in the seventeenth century and highlighting the great names of the nineteenth century.

Chapter 2 outlines in three pages the methods of microscopical demonstration available to the microbiologist; rather too briefly in view of the fact that the book is copiously illustrated with photomicrographs and electron micrographs and the lay reader would probably like to know a little more about how they were obtained. This is followed by a short chapter (five pages) on "Diagnostic Bacteriology".

The bulk of the text is presented in Chapter 4 under the title "Bacterial Anatomy" and the various anatomical features-flagella, capsules, cell wall, internal composition and endospores-are dealt with under subheadings.

Chapter 5 takes a brief look at bacteriophages and Chapter 6 at bacterial genetics. Chapter 7 has three subheadings, "The Myxobacteria", "The Streptomycetes" and "Therapeutic Substances". Chapter 8 deals with the "Mycoplasmataceae". There follows a 14-page glossary, a page of references and a subject index.

There are about 60 photographic plates and about 20 line drawings. In general, the plates are of a very high standard, some of them spectacular (even though they have been printed elsewhere). It is a good thing, too, that the references to the papers from which tho plates have been taken have been retained.

One of the problems about this book seems to have been an uncertainty about the level at which it should be maintained. It is written in a straightforward, sometimes over-simple way, yet the list of references includes some advanced texts that could scarcely be recommended reading for the layman. Over-simplification has also led to some odd statements, for example: "Two points closer together than half the wavelength of white light cannot be seen as 